PANORAMA

ISSN: 1909-7433

ISSN: 2145-308X

ednorman@poligran.edu.co

Politécnico Grancolombiano

Colombia

\title{
PROCESO DE APRENDIZAJE EN LA PANDEMIA
}

Abril Lancheros, Myriam Stella

PROCESO DE APRENDIZAJE EN LA PANDEMIA

PANORAMA, vol. 15, núm. 28, 2021

Politécnico Grancolombiano, Colombia

Disponible en: http://www.redalyc.org/articulo.oa?id=343965146010

Institución Universitaria Politécnico Grancolombiano

Institución Universitaria Politécnico Grancolombiano

\section{(c) (1) 9}

Esta obra está bajo una Licencia Creative Commons Atribución-NoComercial-SinDerivar 4.0 Internacional. 


\title{
PROCESO DE APRENDIZAJE EN LA PANDEMIA
}

\author{
LEARNING PROCESS IN THE PANDEMIC \\ PROCESSO DE APRENDIZAGEM NA PANDÊMICA \\ Myriam Stella Abril Lancheros msabril00@hotmail.com \\ Docente universitaria, Colombia
}

PANORAMA, vol. 15, núm. 28, 2021

Politécnico Grancolombiano, Colombia

Recepción: 08 Septiembre 2020

Aprobación: 21 Octubre 2020

Redalyc: http://www.redalyc.org/ articulo.oa?id=343965146010
Resumen: El artículo tiene como objetivo realizar una reflexión sobre el proceso de aprendizaje a nivel interno y externo que la sociedad ha tenido que experimentar como consecuencia de la pandemia (Covid-19). Para lograr dicho objetivo se abordarán las perspectivas de las teorías del aprendizaje, se enfatizará la teoría social cognitiva, desarrollada por Albert Bandura, la cual soporta evidencias de aplicación en diferentes disciplinas sociales y cobra mayor relevancia los mediadores de dicha teoría: a nivel interno, creencias, pensamientos, motivación; a nivel externo, variables ambientales. Como resultado de ello se pretende analizar el comportamiento del ser humano en su proceso de aprendizaje y la influencia de factores externos que debe construir en un entorno continuamente cambiante, lo que demanda del individuo la capacidad de un proceso sistemático de adaptación en el momento de analizar, reflexionar, asimilar y modificar conductas sobre él mismo y su entorno, afectando su respuesta emocional y comportamental. Dicha reflexión permite comprender la desesperanza percibida en algunos humanos ante situaciones dificiles de controlar.

Palabras clave: Aprendizajes, teoría sociocognitiva, determinismo recíproco, pandemia (Covid 19).

Abstract: The article aims to reflect on the internal and external learning process that society has had to experience because of the pandemic (Covid-19). To achieve this objective, the perspectives of learning theories will be addressed, the cognitive social theory, developed by Albert Bandura, which supports evidence of application in different social disciplines, will be emphasized and the mediators of said theory become more relevant: internally, beliefs, thoughts, motivation; externally, environmental variables. As a result of this, it is intended to analyze the behavior of the human being in his learning process and the influence of external factors that he must build in a continuously changing environment, which demands from the individual the capacity of a systematic process of adaptation at the time of analyzing, reflect, assimilate and modify behaviors about himself and his environment, affecting his emotional and behavioral response. This reflection allows us to understand the hopelessness perceived in some humans in situations that are difficult to control.

Keywords: Learnings, sociocognitive theory, reciprocal determinism, pandemic (Covid 19).

Resumo: $\mathrm{O}$ artigo tem como objetivo refletir sobre o processo de aprendizagem interno e externo que a sociedade tem vivido em decorrência da pandemia (Covid-19). Para atingir esse objetivo, serão abordadas as perspectivas das teorias de aprendizagem, enfatizandose a teoria social cognitiva, desenvolvida por Albert Bandura, que suporta evidências de aplicação em diferentes disciplinas sociais e os mediadores dessa teoria tornam-se mais relevantes: internamente, as crenças, pensamentos, motivação; externamente, variáveis ambientais. Com isso, pretende-se analisar o comportamento do ser humano em seu processo de aprendizagem e a influência de fatores externos que devem ser construídos em um ambiente em constante mudança, que exige do indivíduo a capacidade de um processo sistemático de adaptação. na hora de analisar, refletir, assimilar e 
modificar comportamentos sobre si e seu meio, afetando sua resposta emocional e comportamental. Essa reflexão permite compreender a desesperança percebida em alguns humanos em situações de difícil controle.

Palavras-chave: Aprendizagem, teoria sociocognitiva, determinismo recíproco, pandemia (Covid 19).

\section{INTRODUCCIÓN}

El hombre no vive solo en este mundo, los seres humanos se agrupan colectivamente, subsisten en campos, aldeas, ciudades, logrando establecer un entramado de interrelaciones sociales, descubriendo un fenómeno social, no solo por la necesidad de sentirse acompañado, sino para intercambiar ideas, bienes, y asegurar su propia sobrevivencia, mejorando la calidad de vida con grado de satisfacción en aspiraciones sociales, económicas, espirituales, entre otras; como resultado de ello aprenden a construir un grupo social, comparten creencias, hábitos y costumbres que son transmitidos por la familia, cimentando poco a poco la organización de la vida colectiva; incluyen sistemas de comunicación, formas de vinculación, que construyen una sociedad y marcan sus diferencias en características políticas, económicas, geográficas poblacionales y, por ende, culturales.

Con esta construcción y su estructura social inicia la formación y consolidación de patrones en comportamientos colectivos que juegan un rol importante a nivel grupal, analizando sus diferencias en diversidad social e individuales con la apropiación de ideas, creencias, experiencias, comportamientos dando paso a los conocimientos, comprensión y adaptación del complejo proceso social, entendiendo cómo los seres humanos aprendemos a adaptarse a un medio social. Todo este entremado de colectivos, constituye el punto de partida en la aplicación de las teorías de aprendizaje, siendo el puente de análisis del proceso de aprendizaje humano en situaciones incontrolables.

\section{Construyendo aprendizajes con la pandemia (Covid 19)}

El aprendizaje adquirido en la sociedad, relacionado con el Covid-19 es, sin duda, el material de trabajo más importante en la adquisición de cúmulo de conocimientos vivencias, experiencias que el ser humano haya adquirido, siendo el vínculo en la formación y consolidación del tejido de una sociedad. Según la Organización Mundial de la Salud (O.M.S), la pandemia del Covid-19 causada por infección del virus SARSCoV-2 fue notificado por primera vez en Wuhan (China), el 31 de diciembre del año 2019; en algunos países declararon el estado de emergencia en el primer trimestre del año 2020, con un llamamiento al confinamiento domiciliario de toda la población, cuyo objetivo era detener el progreso de la epidemia. Como consecuencia de ello empezó la construcción de saberes, valores, incertidumbres y expectativas, en factores personales, sociales y ambientales. El ser humano debió aprender a modificar su estilo de vida: con este nuevo actor en el ambiente(virus), desconocido para 
el ser humano y su entorno familiar, se tuvo la necesidad de identificar la situación, buscando información por diferentes medios, filtrando y seleccionando la más pertinente para proteger y salvaguardar su vida y la de su entorno más cercano.

En este etapa de aprendizaje, el ser humano tuvo que modificar el proceso de acercamiento social, pues su distancia para interactuar debía ser de dos metros como mínimo. Antes de la pandemia, lo usual era el intercambio de opiniones y experiencias cara a cara, compartir espacios y artefactos del diario vivir, configurando así sus vínculos afectivos, sociales y comportamentales, construyendo una vida colectiva. Por su parte, el nuevo aprendizaje ante una situación que no se puede controlar demanda del individuo tiempo para razonar, analizar y gestionar sus recursos internos y manejar un distanciamiento con su semejante, cumpliendo unas normas sociales, (protocolo de bioseguridad) al sentir la vulnerabilidad de un posible contagio.

Igualmente, se aprendió a interpretar los riesgos del virus, y algunos individuos lanzaban juicios morales, señalando a los que no cumplían las reglas emitidas por los gobernantes. Otros, en cambio, fueron empáticos con la situación de los demás, reduciendo prejuicios y creando grupos colectivos al compartir sus valores, con la posibilidad de administrar los elementos para el manejo de una inteligencia emocional, al ser resiliente adaptándose al cambio aumentando la confianza para el futuro.

Sin duda, la pandemia Covid-19 es un proceso de aprendizaje en el que cada ser humano reflexiona sobre la realidad social, construida desde su propia historia individual, a partir de su bagaje, ideologías, valores, normas, deseos, aspiraciones comunes, distinguiéndose unos de otros, pero que al final somos la unión de ese fenómeno social.

\section{Mirada a las teorias del aprendizaje}

Para la gran mayoría de seres humanos el aprendizaje es continuo; a diario estamos en el proceso de aprender. Según Solomon (2013), el aprendizaje es "como un cambio relativamente permanente en la conducta, provocada por la experiencia” (p.87). El aprendizaje se da a nivel formal e informal al observar actividades en el transcurso de la vida y en cualquier etapa del ciclo vital del individuo. Estos aprendizajes se van asimilando por medio de conocimientos, vivencias, experiencias positivas y/o negativas anclándose

en el interior de cada ser humano, cuyo objetivo es la adaptación a un entorno social con el fin de demostrar unas competencias individuales, habilidades, capacidades y destrezas que se han adquirido en dicho proceso.

Dentro de las teorías del aprendizaje se encuentra la del condicionamiento clásico, descubierta por Iván Pavlov por medio de investigaciones sobre la digestión en los perros.

El condicionamiento clásico ocurre cuando un estímulo que produce una respuesta se aparea con otro estímulo que inicialmente no producía una respuesta por sí misma. Con el tiempo, el segundo estímulo causa una respuesta similar 
debido a que la asociamos con el primer estímulo. Pavlov indujo un aprendizaje condicionado de forma clásica al aparear un estímulo neutral (una campaña), con un estímulo que provoca la respuesta de salivación en los perros (colocó polvo de carne en sus hocicos). El polvo de carne era un estímulo incondicionado (EI), porque de manera natural era capaz de causar la respuesta. Con el tiempo, la campana se convirtió en un estímulo condicionado (EC), que al inicio no provocaba la salivación; sin embargo, los perros aprendieron a asociar la campana con el polvo de la carne y empezaron a salivar ante el sonido de la campana. La salivación de estos caninos producida por el sonido y ahora asociada con la hora de comer, se convirtió en una respuesta condicionada. (Solomón, 2013, p.90)

Desde el punto de vista de la teoría del condicionamiento clásico, el aprendizaje (concepto conductista), se da por la asociación y apareación de estímulos, centrando su atención en las condiciones que produce una conducta; para el caso del proceso de aprendizaje en la pandemia, los estímulos ambientales (virus) y las respuestas del organismo (miedo), se dan por un proceso de asociación estrecha entre un estímulo primario y uno secundario. Como resultado de estas asociaciones, el organismo experimenta un aprendizaje que se evidencia en la modificación de una conducta (normas de bioseguridad). Según esa teoría, el ser humano aprende por asociación y apareamiento de estímulos, y por ende un aprendizaje cognitivo, esto es, constituye un nivel de análisis en la solución de un problema. En este proceso de aprendizaje de asociación de estímulos entran en juego los determinantes relacionados con variables personales y psicológicos de cada ser humano (resolución de problemas, adaptación al cambio, actitud, motivación).

Estudios de la teoría del condicionamiento pavloviano han sido aplicados en las áreas clínica y del consumidor, donde se busca intervenir sobre patrones de comportamiento específicos e indagando las preferencias del consumo. Zambrano y Agudelo (2016) realizaron un estudio que consistió en evaluar el efecto de la simetría facial (SF), a nivel actitudinal, mediante un procedimiento simultáneo de estímulos condicionados e incondicionados con rostros femeninos y tres logos. Los resultados mostraron una mejor evaluación de los rostros con alta simetría facial, un cambio entre las evaluaciones realizadas antes y después a los logos y, finalmente, que la marca asociada a la SF obtuvo una evaluación más positiva. La evidencia en los resultados del estudio confirma la importancia que aún tienen los postulados en las teorías del condicionamiento clásico, cobrando relevancia para este estudio la aplicación en las preferencias de marcas en el comportamiento humano.

Otro estudio relacionado con el condicionamiento pavloviano fue realizado por Becerra y Pinto (2015), que consistió en que por medio de un experimento se sometió a un grupo de estudiantes a una sesión de condicionamientos donde recibieron un total de 132 ensayos consistentes en la presentación de estímulos auditivos y vibraciones de esos ensayos; 66 correspondian a estímulos condicionados reforzados (EC+), que termina con un soplo de aire como estímulo incondicionado (EI), entremezclados con 66 ensayos de estímulo condicionado no reforzado (EC-) por sí solo. En una sesión de prueba, los participantes recibieron una serie de ensayos examinando la RI (respuesta incondicionada) a estímulos 
incondicionados de alta y baja intensidad cuando eran precedidos por los EC+ y EC-. Estos resultados arrojaron una mayor amplitud de la respuesta condicionada (RC) al EC+, en comparación con el ECen el curso del entrenamiento y una mayor amplitud de la respuesta incondicionada (RI) al EC+ cuando los EC fueron probados con un EI de baja intensidad. Una vez más, las teorias del aprendizaje han sido de gran aporte y validación en el comportamiento humano.

\section{El fenómeno generalización de estímulos y de respuesta}

El aprendizaje en los seres humanos se da por la generalización de estímulos, que se refiere a "la tendencia que tienen los estímulos similares a un estímulo condicionado de evocar respuestas condicionadas parecidas" (Solomón, 2013 p.92).

Estudios han evidenciado el papel de la discriminación de estímulos en productos, que es una capacidad adaptativa del ser humano resultado del proceso de aprendizaje e interacción con los estímulos ambientales, por lo tanto, es la forma como los individuos ajustan sus repertorios conductuales, según los contextos, anticipando apropiadamente resultados favorables o desfavorables, como se cita en Tobón (2016).

Según Tobón (2016), la discriminación de marca por parte de un consumidor reflejaria el nivel de aprendizaje obtenido en la interacción (compra, consumo y exposición) con el producto y todo su componente simbólico que lo caracteriza. Este aprendizaje de marca (asociativo o adaptativo), sa da cuando determinadas características emotivamente estimulantes pueden explicar la preferencia y elección sistemática de dicha marca.

Para el caso que nos ocupa, los seres humanos tienden a hacer generalización de estímulos de mensajes o anuncios, y simbología de productos tales como mascarilla, desinfectante, alcohol, contagio, distanciamiento, y mensajes de los medios de comunicación como quédate en casa, conserva el distanciamiento social, entre otros; es decir, los individuos aprenden a dar respuesta ante diferentes estímulos para proteger su vida y la de su entorno, aprendiendo y desaprendiendo, asimilando y adaptando nuevos estilos de vida, influenciados por un contexto medio ambiental, como consecuencia de una situación inesperada, difícil de controlar (mensajes de miedo por un virus, aislamiento, cuarentena) y la influencia que recibe el individuo por la conducta grupal (familiar), siendo necesario acudir a los recursos internos que posee para el manejo de la situación.

\section{Aprendizaje Instrumental}

Otra de las teorías en la que se vislumbra el aprendizaje es la teoría de condicionamiento instrumental, que algunos teóricos denominan teoría 
de recompensa y castigo, que sin duda tiene una aplicación importante para el tema de este estudio.

Skinner demostró sus postulados del condicionamiento instrumental enseñando a los animales a realizar diferentes actividades $\mathrm{y}$ recompensarlos de forma sistemática por las conductas deseadas. A esto lo llamó aprendizaje operante, afirmando que este "ocurre cuando el individuo aprende a desempeñar conductas que producen resultados positivos y evitar los que producen resultados negativos" (Solomón, 2013, p.94). Ahora, aplicando este postulado en el proceso de aprendizaje en la pandemia Covid-19, este se da en un individuo que aprende a leer las señales (rompetráfico) e interpretar las imágenes publicitarias (personas con tapabocas o ropa antifluidos) o escuchar los mensajes emitidos por los medios de comunicación (mantener distanciamiento social de dos metros, aplicar gel antibacterial en las manos e higiene frecuente de las mismas); su respuesta frente al estímulo será positiva al seguir las normas establecidas, incorporando en su proceso de aprendizaje todos los protocolos necesarios, previniendo el contacto social, y así determina la respuesta de mayor satisfacción, evita contagiarse y contagiar a su entorno más cercano. Por el contrario, al omitir e ignorar todas las señales o medidas de bioseguridad, su castigo es la incertidumbre por el posible contagio del Covid-19, es decir, un cambio en su respuesta de conducta, tanto individual como grupal, y asumir un posible castigo por no acatar dichas medidas, como la hospitalización del contagiado.

Algunos estudios reflejan la aplicación de la teoría del condicionamiento instrumental y asociación de estímulos en el comportamiento humano. Según un estudio realizado por Gámez, León y Moreno (2011), en el que su objetivo era que, por medio de un videojuego en cuatro fases de experimentos, los participantes debian defender la ciudad de Andalucía que estaba siendo atacada por mar, aire y/o tierra, empleando armas que se disparaban pulsando distintas teclas del teclado de un ordenador; en cada fase del experiemento los participantes debían aprender a presionar las teclas de diferente color (estímulos), y destruir el objeto de cada fase (consecuencia). Como efecto de cada fase, los resultados evidencian que los participantes aprendieron a establecer una asociación de colores (estímulos) derribando su enemigo en cada etapa del experimento y dando respuesta eficiente de acuerdo con la asociación de cada color, entre una señal de alerta y la destrucción del enemigo. El experimento realizado confirma una vez más la importancia de la teoría instrumental.

Otro estudio llevado a cabo con la aplicación de la mencionada teoría se enfoca en el marco de la salud. Según González et al. (2016), se realizó un experimento de equivalencia de estímulos o procedimiento general de aprendizaje de discriminaciones condicionales, estudiando seguidamente la formación de clases de equivalencia. La muestra incluyó ocho adultos en edades comprendidas entre 20 y 53 años en tratamiento en el programa de atención a trastornos mentales severos. Como instrumento diseñaron tarjetas con diferentes estímulos visuales arbitrarios con base en las propiedades de semejanza (formas circulares) e identificaciòn 
diferencial (dibujos interiores). Para el registro de datos y resultados individuales se elaboró una hoja especificando los datos demográficos de la muestra y observaciones (incidencia o presencia de síntomas positivos). Igualmente, se registró el número de aciertos y errores en las diferentes fases de entrenamiento. Los resultados mostraron que las personas con esquizofrenia pueden adquirir la equivalencia de estímulos tanto en condiciones psicopatológicas de estabilidad como de descompensación de sintomatología positiva intensa. Es decir, los experimentos realizados en el contexto de salud -aplicando la teoría instrumental- da a los profesionales clínicos herramientas para la rehabilitación y recuperación, en este caso para los esquizofrénicos, y usarlos como estudios de caso para ampliar a otras patologías.

Desde el contexto de mercadeo, el aprendizaje instrumental es utilizado en estrategias que persuaden al consumidor para la compra de productos; ejemplo de ello son los comerciales que usan los cereales para niños y ofrecen como obsequio un incentivo, lo que influye en la decisión de compra. De igual manera, la estrategia que utilizan en las grandes superficies, tales como puntos que se acumulan, u oprimir la ruleta para obtener la mitad del valor de las compras realizadas.

\section{Teoria del constructivismo social}

Los orígenes teóricos del constructivismo social, desarrollado por Vygotsky, datan del siglo XX (García, 2020). Lo esencial de esta perspectiva es considerar al individuo como resultado de un proceso histórico y social, afirmando que el conocimiento es un proceso de la dicotomía, interacción del individuo con el medio ambiente, entendiéndose este como la unión sociocultural. Desde este contexto juega un rol importante el sistema cognitivo del individuo en su proceso de aprendizaje, ya que debe ir incorporando en su red de conocimientos sus experiencias a su estructura mental, asimilando, modificando y adaptando esa dicotomía, desarrollando de esta forma sus habilidades sociales y representándola de forma colectiva para el contexto sociocultural de la sociedad. A tono con la teoría, Rivera (2016) añade: "El constructivismo se expresa como óptica educativa que plantea que el desarrollo del individuo tiene lugar producto de las relaciones sociales que distinguen a la actividad humana, lo que garantiza la asimilación de un tipo particular de experiencia histórico social” (p.611).

\section{$\mathrm{Al}$ respecto, la teoría de Vygotsky}

Se centra en que el desarrollo de los humanos puede ser explicado solo en términos de la interacción social que posibilita la interiorización de elementos culturales, como el lenguaje, que nos transmite el grupo humano en el que nacemos. Desde su nacimiento, el ser humano interactúa con sus congéneres en un medio sociocultural específico y tiene experiencias que paulatinamente se van transformando en procesos mentales como la atención, memoria y la concentración. Considera que la internalización es un proceso de autoconstrucción y reconstrucción psíquica, una serie de transformaciones 
progresivas internas, originadas en operaciones o actividades de orden externo, mediadas por signos y herramientas socialmente construidas, siendo el lenguaje el más importante "instrumento de mediación" que proporciona el medio sociocultural y que posibilita la transformación de fenómenos sociales en fenómenos psicológicos. Para él, todas las funciones psicológicas se originan como relaciones entre los seres humanos. (Agudelo \& Estrada, 2012, p.363)

Desde este punto de vista, para el tema de aprendizaje en la pandemia Covid-19, los elementos de dicha teoría se ven reflejados a nivel individual, teniendo en cuenta el cúmulo de experiencias que trae el ser humano (historia), y que ha construido en su esquema mental la incertidumbre de una situación existente en el medio ambiente (virus); luego filtra, categoriza y evalúa la información trasmitida por los medios de comunicación, adaptándola a una realidad, para después ser compartida a nivel colectivo en la sociedad.

Cabe anotar que la construcción de todo este tejido social se da por la dicotomía entre la interacción social del medio ambiente y la conducta del ser humano; en esa línea vale la pena mencionar lo citado por Perlo (2006):

El concepto de conciencia colectiva es el que permite explicar las relaciones entre individuo y sociedad sin introducirse en marcos de comprensión ajenos a la sociología. Los hechos sociales constituyen una conciencia colectiva que ejercerá coerción sobre la conducta de los individuos. De este modo, la sociedad, según la definiera Durkheim "como un sistema de ideas, sentimientos, costumbres" queda por encima del individuo y la conciencia individual sometida a la conciencia colectiva. (p.91)

Es decir, la construcción de conocimientos se permea de acuerdo con las influencias grupales, lo que en últimas tendra importancia para la experiencia individual.

Para evidenciar la importancia de esta teoría, Jusino (2018) realizó un estudio teniendo como base teórica los postulados de Vygotsky para la intervención en las acciones profesionales del trabajo social en Puerto Rico, siendo para esta autora las variables históricas/culturales su base medular. Como conclusión de la investigación afirmó que los trabajadores sociales tienen que tomar en consideración la cultura, la historia y el medio ambiente de sus participantes a la hora de realizar una intervención, así como entender el pasado del participante y promover la empancipación y la búsqueda de soluciones reales. La ética y los derechos humanos deben ser siempre su guía como profesionales.

En la misma línea, Ortiz (2015), dice que la aplicación de esta teoría se evidencia en estudios realizados como método de enseñanza en la Pontificia Universidad Católica del Ecuador; abordó el tema del constructivismo y sus orientaciones generales para el proceso de enseñanza, planteando los postulados básicos del enfoque con los objetivos, contenidos, metodología, técnica, recursos y una evaluación del proceso de enseñanza, considerando el modelo como un eje primordial de un proceso formativo. Sus hallazgos demuestran que la postura orienta la realización de actividades mediante las cuales el estudiante puede tener acceso a la información que la docente desea compartir, y así ampliar sus conocimientos sobre determinado tema, favoreciendo la adaptación 
del estudiante en el medio que le rodea. En el proceso formativo la aplicación de todas las variables metodológicas descritas anteriormente contribuyen a una mejor comprensión del proceso de formación. En cuanto a los objetivos, se considera que lo principal es el cambio cognitivo y afectivo, de tal forma que las personas puedan alcanzar satisfactorios niveles de adaptación en la condición que viven. Dicho estudio plasma la importancia que presenta la teoría constructivista, no solo en el escenario académico, sino tambien en el ámbito sociocultural.

Otro estudio que aplica la teoría constructivista fue realizado por Mena y Bedón (2017), quienes -apoyadas en la teoría constructivista y como modelo didáctico sustentado en tecnologías web- tenían como finalidad incrementar el conocimiento en el área de la teoría de diseño. El planteamiento de la propuesta radicó en el establecimiento de nuevas formas de comunicación con un carácter lúdico e interactivo, en el que la construcción del conocimiento sea compartida, y cuyos medios de comunicación generen nuevas experiencias colaborativas a través de recursos de lenguaje audiovisual y multimedia. La implementación del entorno virtual temático, destinado a potenciar los procesos de enseñanza-aprendizaje, radica en las fases de operacionalización del aula virtual (temática), la cual se fundamenta en la búsqueda de un aprendizaje significativo basado en el descubrimiento (p.3). Es decir, la implementación del modelo constructivista permite que el estudiante obtenga un aprendizaje dinámico apropiándose de sus conocimientos y llevando a la práctica sus contenidos con un aprendizaje colaborativo; de esta forma, afianza todos los conocimientos adquiridos en la interacción con su temática en el aula virtual.

A continuación, se presenta el esquema de los elementos de la teoría del constructivismo social, desarrollada por Lev Vygoskty, aplicada a la pandemia del Covid-19. 


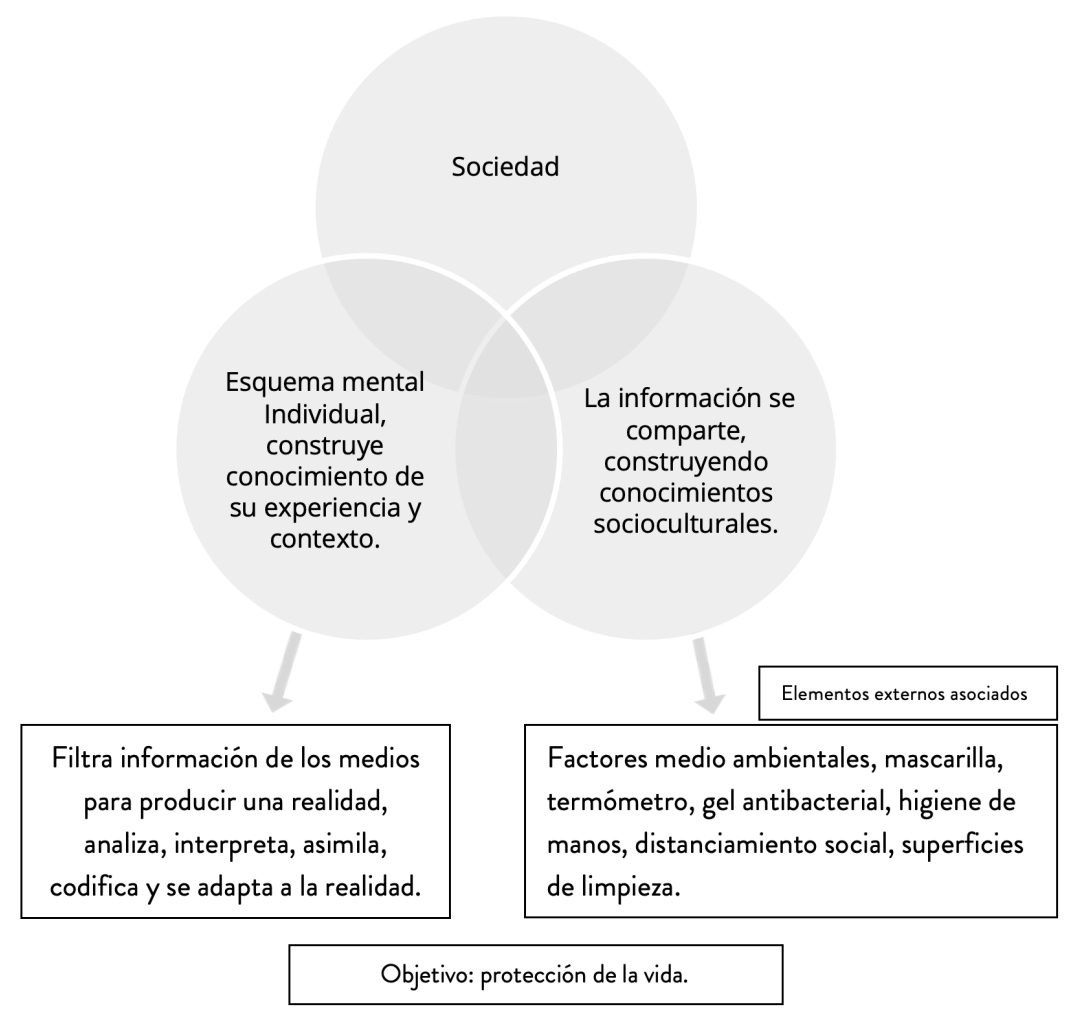

Figura No. 1.

Construcción social del Covid-19. Adaptación teoria Vygostsky

Fuente: elaboración propia (2020).

Lo anterior permite al ser humano asimilar el concepto virus en su estructura cognitiva, dando el sentido y significado de toda la información transmitida por los medios de comunicación, adaptando el nuevo aprendizaje a su conocimiento, reconstruyéndolo a nivel global e incorporándolo a su red de experiencias; asílo relaciona con su diario vivir, su ambiente y su cultura, convirtiéndose en un aprendizaje significativo. Como resultado hay una construcción de tejido social, compartiendo sus nuevas experiencias a un colectivo y apropiándose de ellas.

\section{Teoría del aprendizaje cognoscitivo}

En la dinámica del aprendizaje, los procesos cognitivos son aquellos que se destacan por las representaciones mentales, construcción y transformación de esquemas de acuerdo con conocimientos adquiridos. Para abordar esta teoría se plasman conceptos de diferentes autores, con el objetivo de engranar y enfatizar el objeto del artículo. La teoría de aprendizaje social (T.A.S), desarrollada por Bandura (1986), más adelante se denomina teoría social cognitiva (T.S.C), que enfatiza la relevancia de los factores psicológicos del individuo, y es denominado modelo del determinismo recíproco que considera tres elementos importantes: la interacción con el medio ambiente, el comportamiento y el proceso psicológico individual (ver figura 2). 




Figura No. 2.

Elementos del determinismo recíproco

Fuente: elaboración propia (2020), adaptación teoría Bandura (1987).

Este modelo centra la importancia de los determinantes personales como creencias y motivación, siendo determinantes para el cambio de conductas por las influencias medio ambientales. Por su parte, Assael (2003) afirma:

El aprendizaje cognoscitivo es un proceso de percepción y de asociación de estímulos con respecto a las necesidades de evaluación de marcas, alternativas y valoración del producto para determinar si satisface las expectativas del consumidor. El aprendizaje es equiparable al proceso de toma de decisiones compleja, ante el énfasis en la resolución de problemas. (p.121)

En esta teoría, Sarmiento considera la importancia del aprendizaje como un mecanismo fundamental para su desarrollo, contemplando la interacción social en un entorno que representa un bagaje sociocultural donde inciden mediadores que ayudan al individuo en un desarrollo cognitivo, en el que el ser humano va construyendo conocimientos y significados por sí mismo, partiendo de lo individual a lo colectivo y cimentando un proceso de apropiación del conocimiento.

La sociedad, a nivel de aprendizaje, siempre querrá experimentar y profundizar sobre sus temas de interés, logrando de esta forma revisar y modificar creencias, esquemas pasados e ir alimentando los nuevos aprendizajes, siendo necesario mantenerse motivado para esos nuevos aprendizajes y deseoso sobre la necesidad de ampliar información y apropiarla en su estructura cognoscitiva, como proceso de su sapiencia para compartir con su grupo o colectivo más cercano.

Por su parte, Lahey, como se citó en Jara y Yerry (2018), considera que el aprendizaje social del cual habla Bandura "es un caso del determinismo recíproco; ya que el ambiente recibe una influencia directa de la conducta, por lo que no debemos limitarnos únicamente a pensar que la conducta de las personas son aprendidas, sino que el ambiente también juega un papel importante" (p.26). Al respecto, se debe destacar la influencia que ejerce un virus en el factor conductual del ser humano, pues no está en el control del individuo, sino que se refleja en la gestión que realiza para manejar la situación, adquiriendo aptitudes, actitudes y adaptación al cambio. 
Por otro lado, Solomón (2013), destaca la importancia de los procesos mentales internos. Esta perspectiva considera que las personas son solucionadoras de problemas que usan de forma activa la información del mundo que les rodea para dominar su entorno. Teniendo en cuenta estos conceptos, la teoría social cognitiva cumple un papel fundamental en el proceso de aprendizaje; tiene como mediador principal el proceso mental del individuo en el manejo de administración de recursos propios, en factores del medio ambiente y su posición actitudinal.

Siguiendo la línea de aprendizaje, enfocado en la cognición, Tarpy (2010) define el aprendizaje como un "cambio inferido en el estado mental del organismo, el cual procede de la experiencia e influye de forma relativamente permanente en el potencial del organismo para la conducta adaptativa posterior" (p.20). Desde esta postura, el individuo debe hacer un cambio mental que le permita clasificar la información que recibe del exterior e ir construyendo de forma mesurada su conocimiento anterior, para conectar sus nuevos aprendizajes con la información como eje central del proceso mental.

Como evidencia de lo mencionado, se realizó un estudio aplicando la teoría cognitiva social (Spontón et al., 2018), en la que los autores querían poner a prueba la invarianza estructural de un modelo sociocognitivo en donde la autoeficacia profesional desempeña un rol predictor del burnout y del engagement en el trabajo. Utilizaron dos muestras independientes y heterogéneas de trabajadores españoles $(\mathrm{N}=1.406)$ y trabajadores argentinos $(\mathrm{N}=687)$. Realizaron un estudio ex post facto prospectivo utilizando ecuaciones estructurales (SEM) y análisis multivariante de la varianza (MANOVA) para analizar si existen diferencias en las variables estudiadas en función del país. A nivel general, y como conclusión del estudio, señalan con claridad que las creencias de autoeficacia profesional desempeñan un rol de importancia en el desarrollo del burnout y el engagement de los trabajadores españoles y argentinos. Es decir, la aplicación del modelo sociocognitivo confirma la importancia de las creencias en el ser humano y cómo estas juegan un papel indispensable en el manejo de recursos internos para las personas.

De otro lado, un estudio de las creencias de autoeficacia (Chacón, 2006), concluye: "Los aportes de la teoría sociocognitiva conducen a reflexionar sobre la función de las creencias de autoeficacia en el pensamiento de los educandos" (p.53). Desde este punto de vista, la modificación de las creencias por parte de los profesores influye en la formación del manejo en la segunda lengua.

Otros estudios realizados en el contexto académico validan la importancia de este elemento cognitivo. Carbonero y Merino (2004) realizaron un estudio experimental con el objetivo de fomentar su autoeficacia vocacional, a partir de su madurez vocacional. Para cubrir dicho objetivo facilitaron a los alumnos de educación secundaria y a los orientadores materiales de trabajo que les permitian desarrollar y mejorar, entre otras cosas, su percepción ocupacional de las carreras; con dicha intervención pretenden demostrar el incrementar la expectativa de la autoeficacia, incorporando una serie de actividades que permitan 
valorar positivamente a los sujetos participantes sus logros personales de ejecución en la planificación de la carrera, así como sus objetivos personales en la mejora de autoconocimiento, en el desarrollo de la conducta exploratoria y en la eficacia en la toma de decisiones. El programa de intervención utilizado en este estudio demostró que los alumnos que integraron el grupo experimental mejoran más que los alumnos del grupo control en las variables analizadas: autoconfianza en la toma de decisiones, eficacia en la ejecución de las tareas, la conducta en la búsqueda de información, y el control del ambiente. Como resultado del estudio se detectaron diferencias significativas entre hombres y mujeres, demostrando en estas una mayor madurez vocacional y una actitud más positiva hacia las opciones académicas y profesionales (p.6).

Los estudios citados reflejan la importancia de la teoría sociocognitiva. A nivel académico y cultural, los individuos cimientan sus pensamientos, interactúan con sus experiencias y es a partir de este proceso cognitivo que edifican los conocimientos con cambios relativos en su aprendizaje. Las influencias del medio y la conducta de los individuos dejan ver la importancia de comprender elementos que describe Piaget como la asimilación y acomodación, pues estos se anclan en el proceso de aprendizaje y se van labrando de acuerdo con su experiencia individual.

\section{METODOLOGÍA}

El documento descrito fue realizado de forma empírica y exploratoria, enfocada desde el punto de vista profesional, apoyada en las teorías del aprendizaje y autores como Bandura y Vygoskty, entre otros.

Del mismo modo, se revisaron artículos que cobran relevancia para la aplicación de cada uno de los postulados descritos, tanto a nivel académico como clínico, dichos estudios fueron analizados y enfocados en comprender y profundizar el fenómeno Covid-19, con búsqueda en bases de datos especializadas de forma sistemática, explorando y analizando cada una de las teorías descritas y aplicándolas a la situación del Covid-19. Lamentablemente, por la situación de la pandemia se dificultó realizar un método con mayor rigurosidad y objetividad. Con lo anterior, este análisis abre nuevas oportunidades y está abierto a ser aplicado a un estudio descriptivo, tomando una muestra de la población en miras de aplicar los postulados teóricos y obtener datos reales y comparativos para una segunda fase del artículo, permitiendo así contrastar el análisis de reflexión con la realidad que vive la sociedad.

\section{CONCLUSIONES}

En la actual sociedad, el aprendizaje de cada individuo es diferente; el ser humano da una interpretación al mundo desde sus vivencias, nunca corresponde a las experiencias de un colectivo; sin embargo, las experiencias individuales forman un entramado sociocultural, que lleva a formar parte de una representación sociocultural en cualquier sociedad, 
y que se van alimentando a lo largo del tiempo con el aporte de cada ser humano, compartiendo sus diferentes aprendizajes y enriqueciendo dicho tejido social.

En los distintos momentos históricos que hemos vivido entran a jugar un rol importante los mediadores de trasmisión de información, los diferentes medios de comunicación, y es el individuo en sí quien canaliza toda la información, la apropia a su estructura cognitiva aumentando sus conocimientos, aceptándola y adaptándola a una realidad social, comparándola con la realidad del colectivo (otros seres humanos). Los postulados teóricos expuestos permiten la aplicación de los mismos en diferentes escenarios de la vida; para el caso del Covid-19, la sociedad ha tenido que aprender a manejar una situación de incertidumbre y expectativa, y es que si bien tanto los refuerzos positivos como negativos entran en la ecuación de estos aprendizajes para mantener o extinguir conductas de pánico, estrés, miedo, entre otras; también es indispensable la resiliencia del ser humano para manejar una situación que es dificil de controlar.

No se puede dejar a un lado las teorías cognitivas y de construcción social; su aporte a la sociedad son la conexión para comprender las variables internas y externas de los individuos, desarrollando un potencial para el manejo de situaciones inesperadas y que logran cambiar los estilos de vida en la sociedad.

\section{APORTES}

Las teorías de aprendizaje son la puerta de entrada para el enriquecimiento de aplicaciones en diferentes áreas sociales, suministran los elementos para abrir un cúmulo de experiencias y vivencias en cualquier situación del diario vivir. Profundizar sobre cada una de ellas da las herramientas para la comprensión del comportamiento del ser humano, incluyendo las estructuras de su repertorio conductual.

En la sociedad, a través de la historia, las pandemias han dejado un cúmulo de experiencias, permitiendo así revisar y profundizar situaciones similares a las vividas en el inicio del siglo XXI, que posibilitan entender el manejo de una situación desconocida para muchas personas de una sociedad. Posiblemente en la creación de una cultura de aprendizaje se logre aplicar y dar un manejo en diferentes factores que le ayuden al ser humano a identificar herramientas, tanto internas como externas, para evitar su desesperanza aprendida.

En todos los seres humanos están presentes los determinantes personales, ambientales y conductuales; todos estos deben estar interrelacionados con sus recursos propios, llegando así a un manejo de la inteligencia emocional.

\section{REFERENCIAS}

Arellano, C. (2001). Comportamiento del Consumidor. Enfoque América Latina. Ed. Mc Graw Hill. 
Agudelo, M., \& Estrada, P. (2012). Constructivismo y construccionismo social. Revista de trabajo social e intervencion social, (17), 353-378.

Araya, V., Alfaro, M., \& Andonegui, M. (2007). Constructivismo: orígenes y perspectivas. Revista de educación Laurus, 13(24), 76-92. Recuperado de: https://www.redalyc.org/pdf/761/76111485004.pdf

Assael, H. (2003). Comportamiento del consumidor. Un enfoque estratégico. Edit. Cengage Learning.

Bandura, A. (1987). Pensamiento y acción. Barcelona, España: Editorial Martínez Roca.

Becerra, C., \& Pinto, P. (2015). Facilitación y disminución condicionada de la respuesta incondicionada en humanos. Avances en Psicología Latinoamericana, 33(1), 1-14. doi: dx.doi.org/10.12804/ apl33.01.2015.01

Carretero, M. (1997). ¿Qué es el constructivismo? Revista de educación, 39-71. Recuperado de: https://educacionucuenca.webnode.es/news/que-es-el-c onstructivismo.

Carbonero, M., \& Merino, E. (2004). Autoeficacia y madurez vocacional. Psicothema, 16(2), 229-234.

Díaz, C., Tagle, T., Alarcón, P., Quintana, M., Ramos, L., \& Vergara, J. (2013). Estudio de caso sobre las creencias de estudiantes de pedagogía en inglés respecto a la autoeficacia percibida y la enseñanza del idioma. Núcleo, 25(30), 41-67. Recuperado de: http://ve.scielo.org/scielo.php?script=sci _arttext\&pid=S0798-97842013000100002\&lng=es\&tlng=es.

García, J. (2020). El constructivismo en la educación y el aporte de la teoría sociocultural de Vygostky para comprender la construcción del conocimiento en el ser humano. Revista Dilemas Contemporáneos, (2), artículo No. 77. Recuperado de: www.dilemascontemporáneoseducaciónpoliticayvalores.com.

Gámez, A., León, S., \& Moreno, M. (2011). Asociaciones en el aprendizaje instrumental Revista Ciencia Cognitiva, 15-18.

González, P., Beltrán, G., Palma, G., \& Martínez, S. (2016). Explorando el potencial de aprendizaje de personas con esquizofrenia en distintas condiciones psicopatológicas. Revista Clinica y Salud, 27(2), 81-88. http: //dx.doi.org/10.1016/j.clysa.2016.04.003

Jara, M., Olivera, M., \& Yerrén, E. (2018). Teoría de la personalidad según Albert Bandura. Revista JANG, 7(2), 22-35.

Marshall, J. (2010). Motivación y Emoción. Ed. Mc Graw Hill.

Norman-Acevedo, E., \& Daza-Orozco, C. E. (2020). La construcción de contenidos para la enseñanza virtual: retos coyunturales en el confinamiento. Panorama, 14(27), 5-13. https://doi.org/10.15765/pnr m.v14i27.1517

Ortiz, D. (2015). El constructivismo como teoría y método de enseñanza. Sophia: colección de Filosofía de la Educación, 19(2), 93-110.

Páez, J., \& Miguel, V. (2006). La teoría cognitiva y la tecnología instruccional como marco conceptual para los cambios curriculares en la Facultad de Medicina. RFM [online], 29(1), 88-92.

Pailiacho, V., \& Bedón, C. (2017). Aplicación de un entorno informático para teoría del diseño, basado en el constructivismo. 3C TIC: Cuadernos de desarrollo aplicados a las TIC, 6(4), 27-41. DOI: . 
Perlo, C. (2006). Aportes del interaccionismo simbólico a las teorias de la organización. Invenio, 9(16), 89-107. Universidad del Centro Educativo Latinoamericano.

Puga, C. (2007). Hacia la Sociología. 4ta edición. Ed. Pearson.

Rivera, N. (2016). Una óptica constructivista en la búsqueda de soluciones pertinentes a los problemas de la enseñanza-aprendizaje. Revista Educación Médica Superior, 30(3).

Sarmiento, S. (2007). La enseñanza de las matemáticas y las Ntic. Una estrategia de formación permanente. (tesis doctoral, cap. 2) Universitat Roviera I Virgili. (Tarragona, España)

Solomón, M. (2013). Comportamiento del consumidor. Ed. Prentice.

Spontón, C., Castellano, E., Salanova, M., Llorens, S., Maffei, L., \& Medrano, L. (2018). Evaluación de un modelo sociocognitivo de autoeficacia, burnout y engagement en el trabajo: análisis de invarianza entre Argentina y España. Psychologia, 12(1), 89-101. doi: 10.21500/19002386.3226

Tarpy, R. (2003). Aprendizaje: teoría e investigación contemporáneas. Madrid: Ed. Mc Graw Hill.

Tobón, S., \& Pérez, A. (2016) El papel de la discriminacion de estímulos en la lealtad hacia un producto de consumo masivo. Revista unidad y empresa, 18(31), 85-101. doi. 10.12804.

Wood, R., \& Bandura, A. (1989). Social Cognitive Theory of Organizational Management. The Academy of Management Review, 14(3), 361-384.

Zambrano, D., Agudelo, J., Javela, L., \& Cruz, J. (2016). Efectos de una simetría facial alta, media y baja en un condiconamiento clásico de actitudes hacia logos. Perspectivas en psicología, 12(1). Recuperado de: http://dx.doi.org/ 10.15332/s1794-9998.2016.0001.03 